\title{
Grieving Through the Process
}

\author{
Nara Miriam Michaelson ${ }^{1}$ \\ Received: 4 October 2020 / Accepted: 12 January 2021 / Published online: 29 January 2021 \\ (C) Academic Psychiatry 2021
}

After all the heroics are said and done,

Drips at the max, but progress at none.

You ask, "Can you still save my loved one?"

And so starts this final quest.

You begin to process your impending loss, As we go through the stages of Kubler-Ross. We lay out the options but hope you will not gloss Over the choice of just letting him rest.

First comes denial, you believe we are mistaken. There must be an action, some pill still worth taking. New treatments and clinical trials to partake in? There surely must be more we can test.

Then comes the anger, hell hath no fury! Just wait 'til you drag us out in front of a jury! Do everything at once, bang it out in a flurry. You demand the utmost best!

Bargaining then arrives in full force,

You ask for the pastor to plan out your course.

You plead and you beg, your voice is now hoarse.

You'd trade your life for this one request.

Depression is the deepest and saddest of all.

Sitting beside you at the end of a long call, I try to provide some comfort during this lull Until the end time manifests.
He dies peaceful and soft in the middle of the night. We did everything we could, yet we still lost this fight. When I call, you accept that his soul has taken flight To his new home, his new nest.

The sixth stage is meaningful, it lasts the rest of your life. He was your very best friend, you his beloved wife. Every memory you share brings joy in this strife. And for this reason, you still feel blessed.

\section{Poet's Statement}

This poem speaks to the author's experience as a resident taking care of sick patients, while simultaneously empathizing with the emotional turmoil that families face. It uses the Kubler-Ross framework to guide the reader vicariously through the stages of the grieving process. Ultimately, the author aims to provide hope and meaning for families, for herself as a provider, and for the reader through difficult periods of loss.

\section{Declarations}

Conflict of Interest The author declares no competing interests.

Publisher's Note Springer Nature remains neutral with regard to jurisdictional claims in published maps and institutional affiliations.

Nara Miriam Michaelson

Michaelson.nara@gmail.com

1 NewYork-Presbyterian Hospital/Weill Cornell, New York, NY, USA 